\title{
Evaluating the Application of Prospective Nursing Intervention in Elderly Patients Undergoing Gastrointestinal Endoscopes
}

\author{
Chunmei Lin, Chan Chen* \\ Digestive Endoscopy Center, The First Affiliated Hospital, Jinan University, Guangzhou, China \\ Email address: \\ 3120057@qq.com (Chunmei Lin),271043946@qq.com (Chan Chen) \\ ${ }^{*}$ Corresponding author
}

To cite this article:

Chunmei Lin, Chan Chen. Evaluating the Application of Prospective Nursing Intervention in Elderly Patients Undergoing Gastrointestinal Endoscopes. International Journal of Gastroenterology. Vol. 4, No. 1, 2020, pp. 24-26. doi: 10.11648/j.ijg.20200401.16

Received: April 23, 2020; Accepted: May 19, 2020; Published: May 29, 2020

\begin{abstract}
Objective: To evaluate the application of prospective nursing intervention in elderly patients undergoing gastrointestinal endoscopes. Methods: We invested 84 patients to join our study who undergoing gastrointestinal endoscopes. The participant's age was higher than 60 years. The time of receiving gastrointestinal endoscopes is from March 2017 to September 2019. The control group participants receive traditional nursing model. In another group, the intervention group patients receive prospective nursing intervention, we provide suitable preventive nursing measures to the participants. Additionally, we use interview and questionnaires to collect the data from participants, the data include patient characteristics information, incidence of complications and inspection time of gastrointestinal endoscopes. Result: The data of Drop in blood pressure, Intestinal bloating and Abdominal pain is Statistical significance. The relative complications cases of intervention group were less than that of control group in overall [1 (2.4\%) vs $4(9.5 \%), 1(2.4 \%)$ vs $3(7.1 \%), 2(4.8 \%)$ vs $5(11.9 \%)]$. In inspection time of gastrointestinal endoscopes, intervention group participants have better performance than that of control group, the intervention group has shorter Gastroscopy time and Colonoscopy time $(15.62 \pm 1.56$ vs $17.41 \pm 1.42,24.89 \pm 2.77$ vs $27.01 \pm 2.63)$. The data between the intervention group and control group is statistical significance. Conclusion: the prospective nursing intervention has strong influence to improve patient complications situation and reducing inspection time of gastrointestinal endoscopes.
\end{abstract}

Keywords: Prospective Nursing Intervention, Gastrointestinal Endoscopes, Nursing

\section{Introduction}

Gastrointestinal endoscopes are medical devices frequently used for minimally invasive diagnostic procedures [1]. in hospitals worldwide, Gastrointestinal endoscopes had wide application range, such as the diagnosis and examination of gastric cancer, gastric ulcer, duodenal ulcers, and other gastrointestinal conditions [2]. Base on endoscopies report of the Osaka University Hospital, it had approximately 7,000 cases that are performed for diagnosis, examination, and various treatments each year [3]. During gastrointestinal endoscopy, optimal visualization maybe impeded by the presence of foam and bubbles [4]. Order to prevent or reduce bubbles, researchers usually use simethicone which contain solutions are commonly administered to patients undergoing gastroscopy and colonoscopy $[5,6]$. According to the report, its benefit included improving endoscopist and patient satisfaction, and reductions in bloating and abdominal discomfort experienced by patients [7]. There are different kinds of flexible gastrointestinal endoscopes used in medicine. They differ between manufacturers and even between models from the same manufacturer. In addition, infection-control issues during gastrointestinal endoscopy, which are becoming increasingly important, that its major areas contain microbial flora, infections transmitted which are way of endoscope and infections transmitted which between the patient [8].

The prospective nursing intervention is a nursing intervention mode to avoid nursing risk and control nursing quality in advance [9]. Because the nursing risk is a important factor in treatment process. Nursing risk refers to the risk of 
legal liability and financial liability for the medical infringement of the patient's body in the medical care activities [10]. Additionally, nursing care is among the most important components in provision of quality health care [11]. In treatment process, nurses are a critical role who act as patient advocate, their responsibilities are regulating quality care and improving health care values [12]. The Aim of this study is that assess the application of prospective nursing intervention in elderly patients undergoing gastrointestinal endoscopes.

\section{Methods}

\subsection{Participants Enrollment and Study Methods}

We invested 84 patients to join our study who undergoing gastrointestinal endoscopes. The participant's age was higher than 60 years. The time of receiving gastrointestinal endoscopes is from March 2017 to September 2019. In study process, the participants were randomly assigned participants to two groups, that included a control group $(n=42)$ and a intervention group $(n=42)$. The control group participants receive traditional nursing model. Additionally, the intervention group patients receive prospective nursing intervention, we provide suitable preventive nursing measures to the participants. Additionally, we use interview and questionnaires to collect the data from participants, the data include patient characteristics information, incidence of complications and inspection time of gastrointestinal endoscopes. Our researchers collect the data when they agree to join our study.

Their inclusion criteria were: (1) Patient successfully completed gastrointestinal endoscopes; (2) Patients volunteered to participate in follow-up; (3) Patient has no other serious illness. Their withdraw criteria were: (1) The mental state of the patient is unable to judge affairs correctly; (2) Patients apply to withdraw from our study during check or nursing care.

\subsection{Statistical Analysis}

Our data analyzer performed the statistical analysis by SPSS 22.0. The $\mathrm{P}$ value, t-test and chi-square test were associated with collection result were analyzed. Besides, the mean standard deviation for statistical description.

\section{Result}

The Table 1 shows the patient characteristics, the participants of two groups have similar characteristics as they are not statistical significance $(p=0.819 \& p=0.917)$. Thus, the results of the two groups could exclude most of the influencing factors.

Table 1. Patient characteristics.

\begin{tabular}{lll}
\hline Projects & Gender (female) & Age (year) \\
\hline Intervention group $(\mathrm{n}=42)$ & 25 & $72.4 \pm 6.8$ \\
Control group $(\mathrm{n}=42)$ & 26 & $71.9 \pm 7.2$ \\
$\mathrm{t}$ & 0.318 & 0.248 \\
P value & 0.819 & 0.917 \\
\hline
\end{tabular}

In Table 2, it shows the different complications in gastrointestinal endoscopes process. In particular, the data of Drop in blood pressure, Intestinal bloating and Abdominal pain is Statistical significance. The relative complications cases of intervention group were less than that of control group in overall [1 (2.4\%) vs $4(9.5 \%), 1(2.4 \%)$ vs $3(7.1 \%), 2$ $(4.8 \%)$ vs $5(11.9 \%)]$.

Table 2. Incidence of complications [n (\%)].

\begin{tabular}{|c|c|c|c|c|c|}
\hline Projects & Bowel perforation & Anesthesia accident & Drop in blood pressure & Intestinal bloating & Abdominal pain \\
\hline Intervention group $(n=42)$ & $0(0.0 \%)$ & $0(0.0 \%)$ & $1(2.4 \%)$ & $1(2.4 \%)$ & $2(4.8 \%)$ \\
\hline Control group $(n=42)$ & $1(2.4 \%)$ & $1(2.4 \%)$ & $4(9.5 \%)$ & $3(7.1 \%)$ & $5(11.9 \%)$ \\
\hline $\mathrm{t}$ & 0.867 & 0.561 & 8.161 & 11.141 & 9.813 \\
\hline$P$ value & 0.410 & 0.551 & 0.004 & $<0.001$ & $<0.001$ \\
\hline
\end{tabular}

The Table 3 indicate the inspection time of gastrointestinal endoscopes in intervention group and control group. In particular, intervention group participants have better performance than that of control group, the intervention group has shorter Gastroscopy time and Colonoscopy time ( $15.62 \pm 1.56$ vs $17.41 \pm 1.42,24.89 \pm 2.77$ vs $27.01 \pm 2.63)$. The data between the intervention group and control group is statistical significance.

Table 3. Inspection time of gastrointestinal endoscopes (Mean $\pm S D)$.

\begin{tabular}{llll}
\hline Projects & Cases & $\begin{array}{l}\text { Gastroscopy } \\
\text { time (min) }\end{array}$ & $\begin{array}{l}\text { Colonoscopy } \\
\text { time (min) }\end{array}$ \\
\hline Intervention group $(\mathrm{n}=42)$ & 42 & $15.62 \pm 1.56$ & $24.89 \pm 2.77$ \\
Control group $(\mathrm{n}=42)$ & 42 & $17.41 \pm 1.42$ & $27.01 \pm 2.63$ \\
$\mathrm{t}$ & - & 7.107 & 15.292 \\
P value & - & $<0.001$ & $<0.001$ \\
\hline
\end{tabular}

\section{Discussion and Conclusion}

Gastrointestinal endoscopes were now a common procedure. An estimated 12.7 million gastrointestinal and 880 000 pulmonary flexible endoscopies were performed in the United States in 2017 [13]. There is mainly used for the detection of upper digestive tract diseases, such as early oesophageal or gastric cancer [14]. The gastrointestinal endoscopes produced a great many of images in each diagnosis. But the collected information does not contain the lesion information from the huge image dataset. So clinical doctors usually spend large efforts and long periods of time before making a diagnosis [15]. Gastrointestinal endoscopes are an important tool for monitoring extremely ill patients. As patients are also likely to harbor high loads of bacteria and 
viruses, which may lead to high-level contamination on instruments, the patients had increased risk from introduced pathogens [16]. There are many case reports of bacterial infection after endoscopy, some of which report transmission of pathogenic organisms from patient to patient $[17,18]$. Base on the report, an increase in risk of pathogen transmission has been related to unacceptable cleaning and disinfection, the risk from failure to sterilize accessory equipment, incorrect germicide use, improper drying, or defective equipment [19]. However, there have been few direct attempts to assess the efficacy of these regimes, to validate recommendations about lab-oratory monitoring of decontamination procedures, or to pinpoint the factors leading to infect.

Base on above research result, the prospective nursing intervention has strong influence to improve patient complications situation and reducing inspection time of gastrointestinal endoscopes. In incidence of complications research, intervention group has very few complication cases in gastrointestinal endoscopes, even some cases of complications do not exist, such as bowel perforation and anesthesia accident. In addition, the complications cases of intervention group are obviously less than the complications cases of control group. In inspection time of gastrointestinal endoscopes research, intervention group also had better performance in the result, intervention group only spend less time to finish gastrointestinal endoscopes. The result indicates the prospective nursing intervention can improve efficiency of gastrointestinal endoscopes. In limitation, the study results only indicate the prospective nursing intervention can improve the performance of elder patient's gastrointestinal endoscopes, not all age group's patients. Additionally, the sample size is too small so that it limits a part of research result and reduce the gap of between different data.

\section{References}

[1] Kovaleva J, Peters FTM, van der Mei HC, Degener JE. Transmission of infection by flexible gastrointestinal endoscopy and bronchoscopy. Clin Microbiol Rev. 2016; 26: 231-54.

[2] Cattoir L, Vanzieleghem T, Florin L, Helleputte T, De Vos M, Verhasselt B, et al. Surveillance of endoscopes: comparison of different sampling techniques. Infect Control Hosp Epidemiol. 2017; 38: 1062-1069.

[3] Visrodia K, Hanada Y, Pennington KM, Tosh PK, Topazian MD, Petersen BT. Duodenoscope reprocessing surveillance with adenosine triphosphate testing and terminal cultures: a clinical pilot study. Gastrointest Endosc. 2017; 86: 180-186.

[4] Wu L, Cao Y, Liao C, Huang J, Gao F. Systematic review and meta-analysis of randomized controlled trials of Simethicone for gastrointestinal endoscopic visibility. Scand J Gastroenterol 2015; 46: 227-235.
[5] Rosa BJ, Barbosa M, Magalhaes J, Rebelo A, Moreira MJ, Cotter J. Oral purgative and simethicone before small bowel capsule endoscopy. World J Gastrointest Endosc 2016; 5: 67-73.

[6] Saltzman JR, Cash BD, Pasha SF, Early DS, Muthusamy VR, Khashab MA, et al. Bowel preparation before colonoscopy. Gastrointest Endosc. 2015; 81: 781-794.

[7] Neale JR, James S, Callaghan J, Patel P. Premedication with $\mathrm{N}$-acetylcysteine and simethicone improves mucosal visualization during gastroscopy: a randomized, controlled, endoscopist-blinded study. Eur J Gastroenterol Hepatol 2017; 25: 778-83.

[8] Nelson DB. Infection control during gastrointestinal endoscopy. JLab Clin Med. 2015; 141: 159-67.

[9] Estrada A, Tsao NW, Howren A, et al. Utility of electronic medical records in community rheumatology practice for assessing quality of care indicators for gout: a feasibility study. J Clin Rheumatol 2018; 24 (2): 75-79.

[10] Lucini FR, Fogliatto FS, da Silveira GJC, et al. Text mining approach to predict hos-pital admissions using early medical records from the emergency department. Int J Med Inf 2017; 100: $1-8$.

[11] Ali MM. A conceptual framework for quality of care. Materia Socio Medica. 2012; 24 (4): 251-261.

[12] Leslie WH, et al. Quality and nursing: Moving from a concept to a core com-petency. Urologic Nursing. 2018; 28 (6): 417-426.

[13] Spach DH, Silverstein FE, Stamm WE. Trans- mission of infection by gastrointestinal endoscopy. Ann Int \&led 2018; 118: $117-128$.

[14] Iakovidis DK, Koulaouzidis A. Software for enhanced video capsule endoscopy: challenges for essential progress. Nat. Rev. Gastro. Hepat. 2015; 12 (3), 172-186.

[15] Liedlgruber M, Uhl A. Computer-aided decision support systems for endoscopy in the gastrointestinal tract: a review. IEEE Rev. Biomed. Eng. 2016; 4 (4): 73-88.

[16] ickery K, Bisset L, Selby W, West R, Catterson D, Cossart YE. Bloodborne virus transmission during endoscopy-viral prevalence or decon-tamination breakdown? In: Jilbert AR, Grgacic EVL, Vickery K, BurrellC, Cossart YE, editors. Proceedings 11th International Symposium on Viral Hepatitis and Liver Disease. Melbourne: The Australian Centre for Hepatitis Virology. 2015: 344-6.

[17] Moayyedi P, Lynch D, Axon A. Pseudomonas and endoscopy. Endos-copy. 2018; 26: 554-558.

[18] Spach DH, Silverstein FE, Stamm WE. Transmission of infection by gastrointestinal endoscopy and bronchoscopy. Ann Intern Med. 2014; 118: 117-28.

[19] Weber DJ, Rutala WA, DiMarino AJ Jr. The prevention of infection fol-lowing gastrointestinal endoscopy: the importance of prophylaxis andreprocessing. In: DiMarino AJ Jr, Benjamin SB, editors. Gastrointestinaldiseases: an endoscopic approach. Thorofare, NJ: Slack Inc. 2016: 87-106. 